\title{
Intrauterine Alcohol Exposure Disturbs Trabecular Morphology in the Sprague Dawley Rat Humerus Epiphysis up to 3- Weeks Postnatally
}

\author{
La Exposición al Alcohol Intrauterino Altera la Morfología Trabecular en la Epífisis \\ del Húmero de la Rata Sprague Dawley hasta 3 Semanas Después del Nacimiento
}

Diana Pillay ${ }^{1}$ \& Robert Ndou ${ }^{2}$

PILLAY, D. \& NDOU, R. Intrauterine alcohol exposure disturbs trabecular morphology in the Sprague Dawley rat humerus epiphysis up to 3-weeks postnatally. Int. J. Morphol., 39(5):1436-1442, 2021.

SUMMARY: Gestational alcohol exposure inhibits neurological as well as bone growth and development both in fetal and postnatal life. Stunted stature, osteoporosis and fractures in adult life are some of the adverse effects. While the impact of intrauterine alcohol on the brain has been extensively investigated, studies on the effects on bone are relatively few. Therefore, our study aimed to examine the impact of prenatal alcohol exposure on bone microarchitecture in 3-week-old rats using Micro-focus X-Ray Computed Tomography (Micro CT). Time mated pregnant Sprague Dawley dams (13) were randomly placed into 3 groups: ethanol ( $\mathrm{n}=5$ ), saline control $(n=5)$ and untreated control $(n=3)$. The former 2 groups received treatment with $0.015 \mathrm{ml} / \mathrm{g}$ of $25.2 \%$ ethanol and $0.9 \%$ saline, respectively, for the first 19 days of gestation. The untreated group received no treatment. The pups remained with their dams until termination at 21 days of age. From each dam, 2 pups were collected resulting in: ethanol $(n=10)$, saline controls $(n=10)$ and untreated controls $(n=6)$. The humeri of the pups were dissected and scanned using a 3D- $\mu$ CT scanner (Nikon XTH 225L) at $15 \mu \mathrm{m}$ resolution. Trabecular and cortical parameters were analysed using Volume Graphics Studio® software following reconstruction. Results showed a decrease in trabecular size, spaces, thickness, and volume. There was a decrease in cortical bone area in the ethanol group compared to the controls. These findings may suggest that osteoporosis and fractures seen as gestational alcohol effects may be due to compromised trabecular structure.

KEY WORDS: Microarchitecture; Trabeculae; Humerus; Osteoporosis; Prenatal alcohol.

\section{INTRODUCTION}

Knowledge of the risks associated with alcohol consumption in pregnancy is widely disseminated (Chaudhuri, 2000), however, members of many communities continue to drink in pregnancy. This is the case both in developed and developing countries. For example, in Canada $(10 \%)$ and the United States (15\%) women drink alcohol in pregnancy, with approximately $3 \%$ reported as binge drinking in both countries (Popova et al., 2017). In South Africa, a developing country, a prevalence of $25 \%$ drinking in pregnancy was reported (Tomlinson et al., 2014).

Most children born to mothers who consume alcohol during pregnancy get Fetal Alcohol Spectrum Disorder (FASD) (Chaudhuri; Simpson et al., 2005). The neurological aspects and facial dysmorphology associated with this condition have been widely investigated, with little on the osteological aspects. Despite short stature being a major feature of FASD, the literature on bone development in prenatal alcohol exposure has received relatively less attention. The few studies investigating the skeletal aspects of gestational alcohol exposure (Chaudhuri; Snow \& Keiver, 2007) do not explore trabecular morphological parameters using computed tomography up to 3 weeks postnatally.

Rodent studies (Simpson et al.; Snow \& Keiver) have established that gestational alcohol exposure suppresses the longitudinal growth of fetal bone and affects fetal osseous tissue mineralization. In support of this, Miralles-Flores \&

\footnotetext{
${ }^{1}$ School of Anatomical Sciences, Faculty of Health Sciences, University of Witwatersrand, Johannesburg, 7 York Road, Parktown, 2193, South Africa. ${ }^{2}$ Department of Anatomy and Histology, School of Medicine, Sefako Makgatho Health Sciences University, Ga-Rankuwa, Pretoria, 0204, South Africa. The study received funding from the National Research Foundation of South Africa; Grant number: TTK160826186551.
} 
Delgado-Baeza (1992), suggested that intrauterine alcohol exposure antagonises the growth plate in long bones due to impaired cell function in rats. This results in shorter bones that may explain the stunted growth observed on postnatal life (Simpson et al.; Snow \& Keiver).

Prenatal alcohol exposure affects the balance of osteoclasts and osteoblasts resulting in weak bones and developmental disturbances in the offspring (Chen et al., 2012). It is suggested that the bone weakness is owed to the trabecular morphological properties. Once osteoclasts outperform the bone matrix deposition by osteoblasts, it is envisioned that trabecular may be thinner, fewer, and more spaced out. However, we have not found studies that investigate this proposition using Micro $\mathrm{CT}$ in rats exposed to alcohol during gestation. Considering the above, we sought to understand whether exposure to alcohol during the prenatal duration would affect bone postnatal development.

\section{MATERIAL AND METHOD}

Breeding and animal husbandry. The research protocol with animal experimentation was approved by the Animal Ethics Committee, University of Witwatersrand (AESC 2015/27/ 15C). A total of 13 time-mated Sprague Dawley (SD) rats bred and kept at the Central Animal Services (CAS, University of Witwatersrand were used. These animals were maintained under pathogen free conditions, temperature-controlled environment $\left(23^{\circ} \mathrm{C} \pm 2^{\circ} \mathrm{C}\right)$ and a 12-hour light/dark cycle. Pregnant dams were individually housed in standard transparent cages, with free movement within the enclosures and unrestricted access to tap water and standard rodent diet.

Group allocation and Micro CT. Time mated pregnant Sprague Dawley dams (13) were randomly placed into 3 groups: ethanol $(n=5)$, saline control $(n=5)$ and untreated control $(n=3)$. Fewer animals were used in this group $(n=3)$ to lessen the number of animals required for the study. The former 2 groups received treatment with $0.015 \mathrm{ml} / \mathrm{g}$ of 25.2 $\%$ ethanol and $0.9 \%$ saline, respectively, for the first 19 days of gestation.The first day of pregnancy was determined by the presence of a vaginal plug. The untreated group received no treatment. The pups remained with their dams until termination at 21 days of age by a lethal pentobarbital intraperitoneal injection. From each dam, 2 pups were collected resulting in: ethanol $(n=10)$, saline controls $(n=$ 10) and untreated controls $(n=6)$. The humeri of the pups were then dissected and wrapped in Styrofoam. A Nikon XTH 225/320 LC scanner was used for three-dimensional Micro-focus X-ray Computed Tomography (Micro CT) using the scanning parameters outlined in Table I.
Table I. Scanning parameters used in the Nikon XTH 225/320 LC scanner.

\begin{tabular}{ll}
\hline Parameter & Value \\
\hline X-ray voltage & $70 \mathrm{kv}$ \\
X-ray current & $400 \mu \mathrm{a}$ \\
Filter & $1 \mathrm{~mm}$ aluminium \\
Scanning resolution & $15 \mu \mathrm{m}$ \\
Tomographic rotation & 360 degrees \\
Rotation step & 1 degree \\
Frame averaging & 4 \\
Scan duration & 8 minutes \\
\hline
\end{tabular}

Parts of the humerus and trabecular parameters studied. Following reconstruction, VG studio Max @3.2 was used for data analysis as previously described (Bouxsein et al., 2010). Bone length was measured, and the epiphysis (proximal and distal) (Fig. 1) were assessed for volume. The following trabecular morphometric parameters: bone volume to total volume (BV/TV), trabecular thickness ( $\mathrm{TbTh}$ ) trabecular number $(\mathrm{TbN})$ and trabecular spacing $(\mathrm{TbSp})$ were assessed.

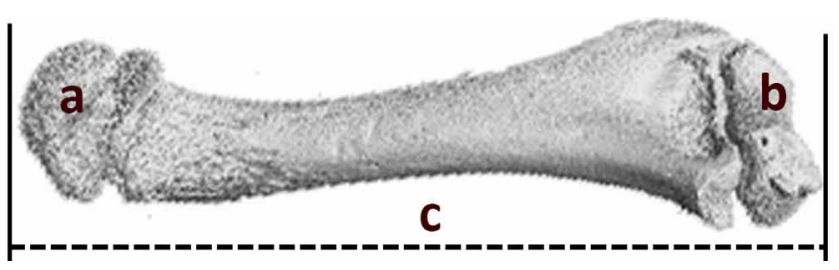

Fig. 1. Three-dimensional reconstruction of the humerus showing the parts that were investigated. (a), proximal epiphysis; (b), distal epiphysis; (c), full humerus length (Image courtesy of R. Ndou).

Data analysis. The data were managed in Microsoft Excel 2016 (Microsoft Corporation) and analysed using SPSS ${ }^{\circledR}$ version 25 (IBM®). ANOVA with LSD post-hoc was used for multiple group comparisons of means. Binary logistic regression was used to predict group membership into either the ethanol or saline control group. Significance level was set at $\mathrm{p}<0.05$.

\section{RESULTS}

Bone length and epiphyseal volume. All three groups in the study exhibited similar humerus bone length. The ethanol group had a mean of $15.49 \mathrm{~mm} \pm 0.46$ compared to the saline $($ mean $=15.29 \mathrm{~mm} \pm 0.57)$ and untreated controls $($ mean $=15.56 \pm 0.36)(p=0.29)($ Fig. $2 a)$. The size of the epiphysis showed regional similarity in the proximal and distal epiphysis with respect to study groupings. In the 


\section{Bone length}

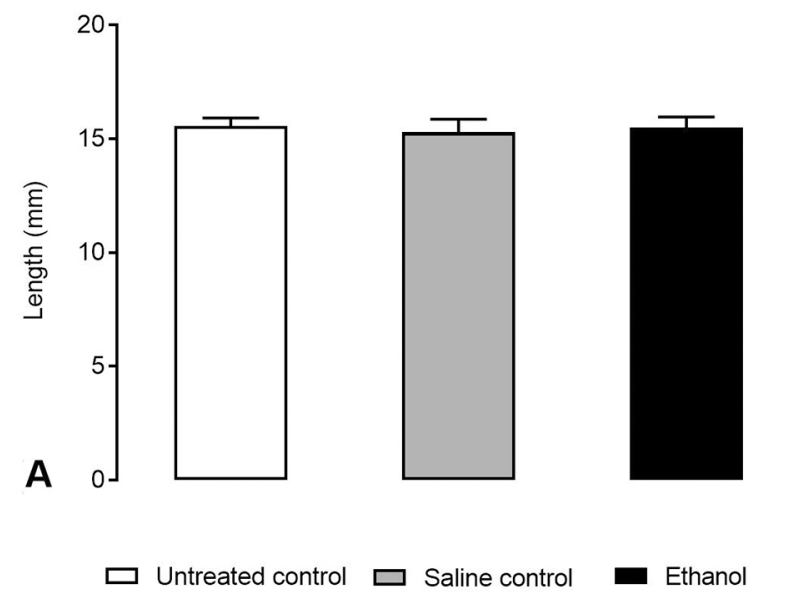

Epiphysis volume
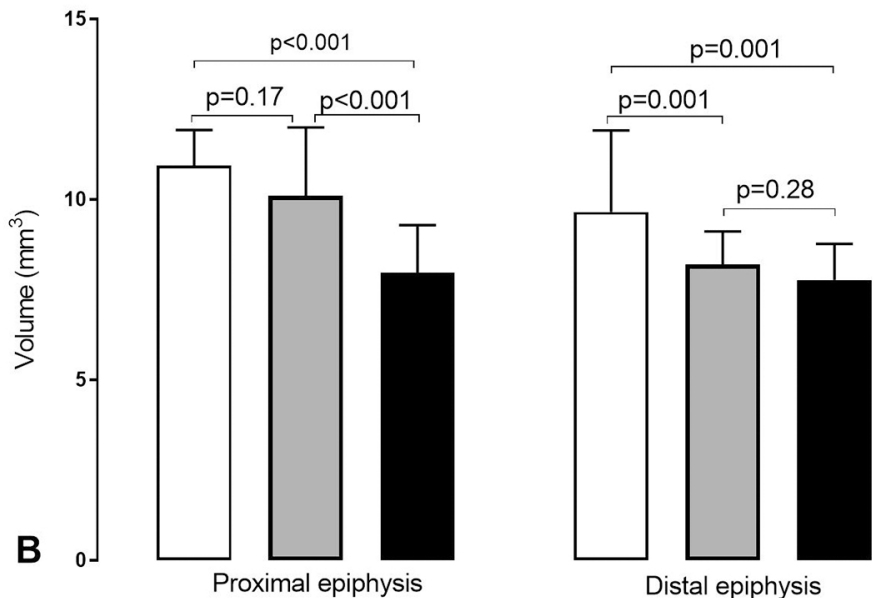

Fig. 2. Size estimation; (a), Bone length;(b). Epiphyseal volume.Mean values are given and error bars represent standard deviation.

proximal epiphysis the largest volume was seen in the untreated $\left(\right.$ mean $\left.=10.94 \mathrm{~mm}^{3} \pm 0.99\right)$ and saline controls $\left(\right.$ mean $\left.=10.11 \mathrm{~mm}^{3} \pm 1.89\right)$ compared to the ethanol group (mean $=7.96 \mathrm{~mm}^{3} \pm 1.33$ ( $\mathrm{p}<0.001$ for both comparisons). The control groups had a negligible difference $(\mathrm{p}=0.17)$ (Fig. $2 b)$. In the distal epiphysis, the untreated group (mean = $9.65 \mathrm{~mm}^{3} \pm 2.27$ ) had the largest volume compared to the saline controls (mean $\left.=8.2 \mathrm{~mm}^{3} \pm 0.92\right)$ and the ethanol group (mean $\left.=7.7 \mathrm{~mm}^{3} \pm 1\right)$ showing the smallest volume $(\mathrm{p}=0.001$, for both comparisons) (Fig. 2b). There were no significant differences detected for the ethanol and saline groups $(\mathrm{p}=0.28)$ (Fig. 2b).

\section{Trabecular morphometry}

Bone to total volume ratio (BV/TV). In the proximal region, the bone to total volume ratio $(\mathrm{BV} / \mathrm{TV})$ was the smallest in the ethanol group whereas no group differences were observed in the distal region. The untreated (mean $=80.13$ $\% \pm 5.47)$ and saline controls (mean $=79.08 \% \pm 8.72)$ had similar BV/TV in the proximal epiphysis $(\mathrm{p}=0.76)$. The ethanol group $($ mean $=71.59 \% \pm 10.76)$ had less BV/TV compared to the saline controls $(\mathrm{p}=0.01)$ or untreated group $(\mathrm{p}=0.002)$ (Fig. 3a). In contrast, the distal epiphysis showed similarities in the saline (mean $=79.48 \% \pm 7.30)$ and untreated controls (mean $=80.21 \% \pm 6.62)$ which were only marginally lower than the ethanol group (mean $=74.64 \%$ $\pm 10.14)(\mathrm{p}=0.149)$ (Fig. 3a).

Trabeculae thickness (TbTh). Trabeculae were thinnest for the ethanol group in the proximal region, with no group differences in the distal region. In the proximal epiphysis, the ethanol group $($ mean $=0.14 \mathrm{~mm} \pm 0.05)$ exhibited thinnest trabeculae (TbTh) of all three groups in the study (Fig. 3b), being significantly lower than the saline (mean $=0.20 \mathrm{~mm}$ \pm 0.08 ) and untreated group (mean $=0.19 \mathrm{~mm} \pm 0.06$ ) ( $p=0.006$ and $p=0.05$, respectively) (Fig. 3b). Although the ethanol group $($ mean $=0.19 \mathrm{~mm} \pm 0.09$ ) seemed to have thinner trabecular in the distal epiphysis than the saline (mean $=0.23 \mathrm{~mm} \pm 0.09$ ) and untreated controls (mean $=0.21 \mathrm{~mm}$ $\pm 0.09)$, there were no statistical group differences detected $(p=0.394)$ (Fig. 3b).

Trabeculae number (TbN). Trabecular distribution by the study groups showed a similar pattern when stratified by the epiphyseal end (proximal and distal). In the proximal region, the trabecular number $(\mathrm{TbN})$ was highest in the untreated controls (mean $=6.83 \mathrm{~mm}-1 \pm 1.68)$ followed by the saline $($ mean $=5.63 \mathrm{~mm}-1 \pm 0.52)$ and was lowest in the ethanol group (mean $=5.10 \mathrm{~mm}-1 \pm 0.99)$. These differences were significant between the ethanol and untreated controls $(\mathrm{p}<0.001)$ and between the controls $(p=0.004)$ (Fig. 3c). However, no significance was detected between the ethanol and saline controls ( $\mathrm{p}=0.113)$. (Fig 3c). Similarly, the distal epiphysis revealed that the number of trabecular $(\mathrm{TbN})$ was highest in the untreated controls $($ mean $=6.23 \mathrm{~mm}-1 \pm 0.75)$ compared to the saline (mean $=5.39 \mathrm{~mm}-1 \pm 0.42$ ) and ethanol group (mean $=4.53 \mathrm{~mm}-1 \pm 0.1 .52$ ). This difference was significant for the untreated group compared to the ethanol $(\mathrm{p}<0.001)$ or the saline group ( $\mathrm{p}=0.017)$. A comparison of the control groups showed no significant differences $(\mathrm{p}=0.06)$ (Fig. 3c).

Trabeculae spacing (TbSp). Both epiphyseal ends exhibited a similar pattern in the trabecular spacing (TbSp) when stratified by study grouping. In the proximal epiphysis, trabecular spacing was significantly greater in the ethanol 

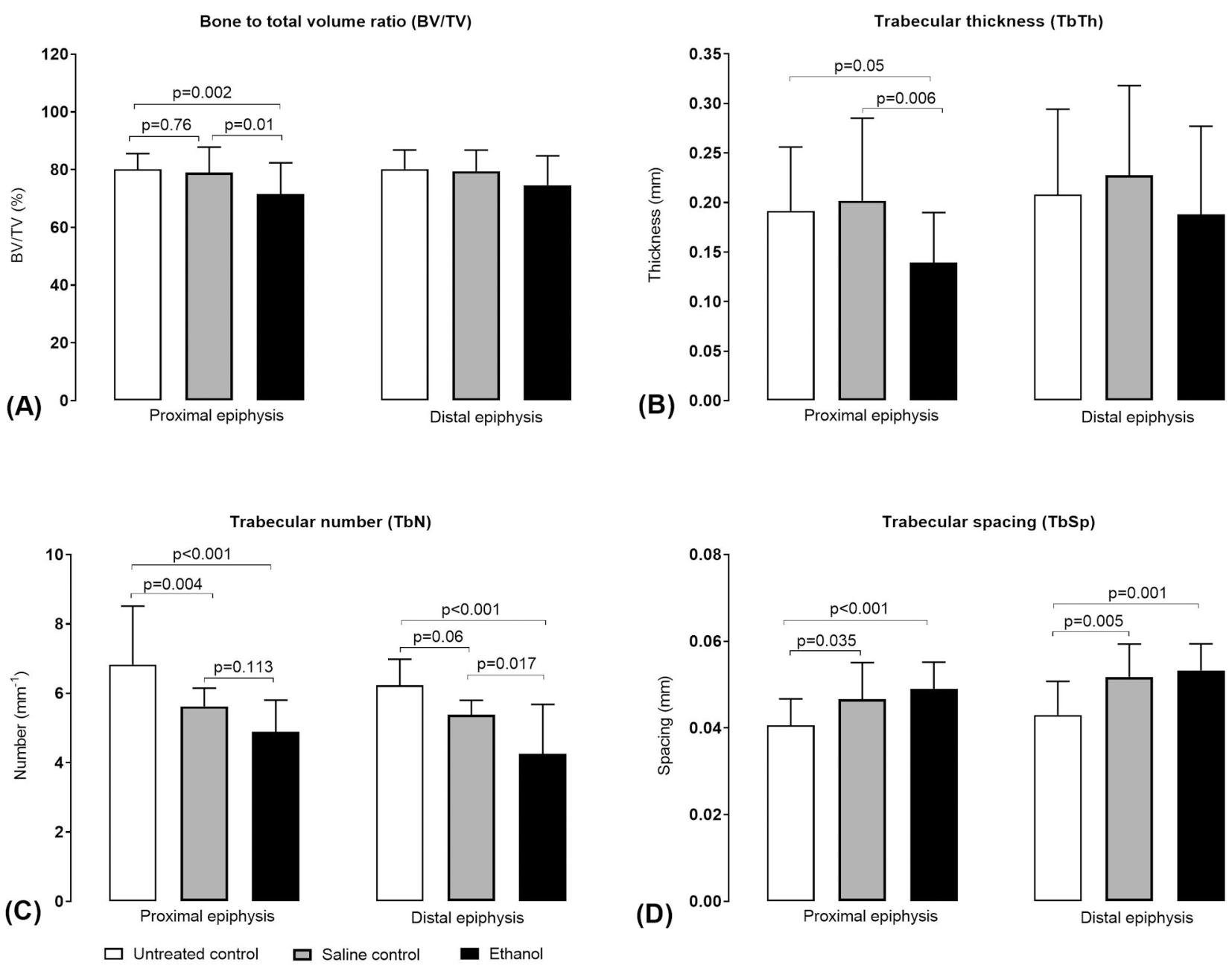

Fig. 3. Trabecular morphometric parameters. Valuesare represented as means; (a), bone to total volume (BV/TV); (b), trabeculae thickness (TbTh); (c), trabeculae number (TbN) and (d), trabeculae spacing (TbSp). Error bars represent standard deviation.

group $($ mean $=0.049 \mathrm{~mm} \pm 0.01)$ compared to saline controls $($ mean $=0.046 \mathrm{~mm} \pm 0.02)$ and untreated group (mean $=$ $0.04 \mathrm{~mm} \pm 0.01)$. This difference was significant for the ethanol compared to the untreated controls $(\mathrm{p}<0.001)$. (Figs. $3 \mathrm{~d}$ and $4 \mathrm{a}-\mathrm{c}$ ). Regarding the controls, the saline group trabecular spacing was significantly greater than in the untreated controls $(p=0.035)$. In the distal epiphysis, trabecular spacing was significantlygreater than in the ethanol group $($ mean $=0.053 \mathrm{~mm} \pm 0.01)$ compared to saline controls (mean $=0.051 \mathrm{~mm} \pm 0.02$ ) and untreated group (mean $=0.043 \mathrm{~mm} \pm 0.01)$ (Figs. $3 \mathrm{~d}$ and $4 \mathrm{~d}-\mathrm{f}$ ). This difference was significant for the ethanol compared to the untreated controls $(\mathrm{p}=0.001)$. Regarding the controls, the saline group trabecular spacing was significantly greater than in the untreated controls ( $\mathrm{p}=0.005)$ (Fig. 3d).
Trabecular morphometric parameters most affected by gestational ethanol

Proximal epiphysis. The effect of gestational ethanol on bone volume to total volume ratio, trabecular thickness, number, and separation was assessed using binary logistic regression in the ethanol and saline control groups. The parameters used could reliably distinguish between the two groups (Table II). A test of the full model against a constant only model was statistically significant, indicating that the predictors as a set, reliably distinguished between ethanol or saline control group membership (Chi-square $=43.716, p<0.001$ with $\mathrm{df}=6$ ). Nagelkerke's R2 of 0.899 indicated a very strong relationship between prediction and grouping. The Wald criterion demonstrated that no specific variable predicted membership 
(Table II). Prediction success overall was 94.9 $\%$ (94.7 \% for the ethanol group and $95.0 \%$ saline controls) (Table III).

Distal epiphysis. The effect of gestational ethanol on bone volume to total volume ratio, trabecular thickness, number, and separation was assessed using binary logistic regression in the ethanol and saline control groups. The parameters used could reliably distinguish between the two groups. A test of the full model against a constant only model was statistically significant, indicating that the predictors as a set, reliably distinguished between ethanol or saline control group membership (Chi-square $=30.793, \mathrm{p}<0.001$ with $\mathrm{df}=6$ ). Nagelkerke's R2 of 0.740 indicated a very strong relationship between prediction and grouping. The Wald criterion demonstrated that only the bone volume to total volume ratio (BVTV) trabecular number $(\mathrm{TbN})$ predicted membership (Table IV). Prediction success overall was $78.6 \%$ $(84.2 \%$ for the ethanol group and $73.9 \%$ saline controls) (Table V).

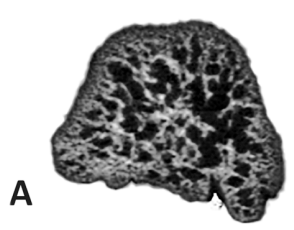

B
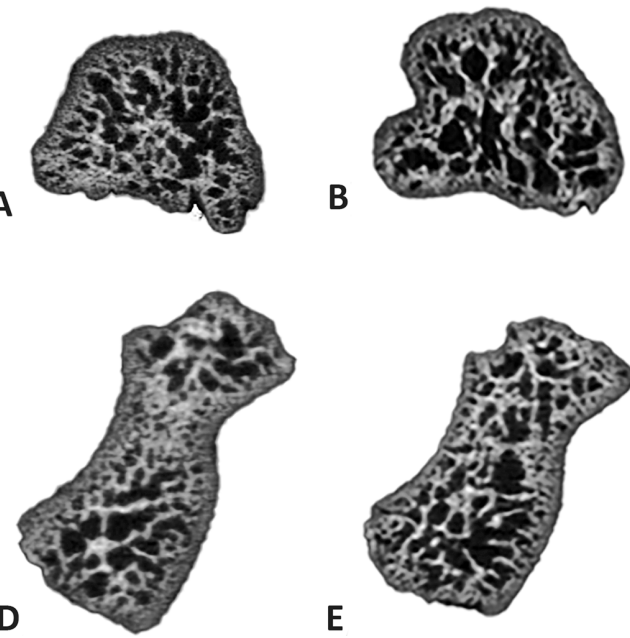

E

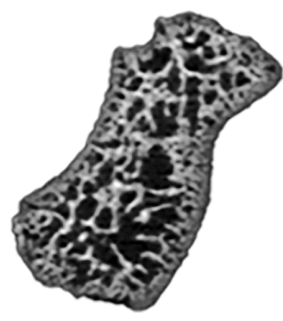

C
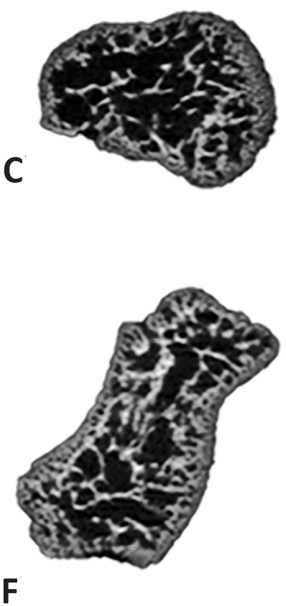

Fig. 4. Trabecular morphology. Representative slices of (a), proximal end in an untreated control showing more trabeculae and less spacing; (b), proximal end in a saline control showing moderate trabeculae and spacing; (c), proximal end of the ethanol group showing fewer trabeculae and wider spacing); (d), distal end of an untreated control showing more trabeculae and less spacing; (e), distal end of saline control showing moderate trabeculae and spacing; (f), distal end of the ethanol group showing fewer trabeculae and wider spacing.

Table II. Humerus osteometric and proximal epiphysis trabecular morphometric parameters in the logistic regression equation. BV/TV, bone volume to total volume; TbTh trabecular thickness; TbN, trabecular number; TbSp, trabecular spacing.

\begin{tabular}{|c|c|c|c|c|c|c|}
\hline \multicolumn{7}{|c|}{ Variables in the logistic regression equation } \\
\hline & $\mathrm{B}$ & S.E. & Wald & df & Sig. & $\operatorname{Exp}(B)$ \\
\hline \multicolumn{7}{|c|}{ Osteometric parameters } \\
\hline Length & 2.872 & 2.457 & 1.366 & 1 & 0.243 & 17.668 \\
\hline Epiphyseal volume & -1.525 & 1.529 & .995 & 1 & 0.319 & 0.218 \\
\hline \multicolumn{7}{|c|}{ Proximal epiphysis trabecular morphometric parameters } \\
\hline $\mathrm{BV} / \mathrm{TV}$ & 315.108 & 221.434 & 2.025 & 1 & 0.155 & 7.073 \\
\hline TbTh & 89.278 & 127.429 & .491 & 1 & 0.484 & 5.926 \\
\hline $\mathrm{TbN}$ & 19.419 & 11.361 & 2.922 & 1 & 0.087 & 27.3 \\
\hline TbSp & 2903.768 & 1644.761 & 3.117 & 1 & 0.077 & 0.2 \\
\hline Constant & -525.136 & 312.276 & 2.828 & 1 & 0.093 & 0.000 \\
\hline
\end{tabular}

Table III. Group membership classification from humerus osteometricand proximal epiphysis trabecular morphometric parameters.

\begin{tabular}{|c|c|c|c|c|}
\hline \multicolumn{5}{|c|}{ Classification table } \\
\hline \multirow{2}{*}{\multicolumn{2}{|c|}{ Observed }} & \multicolumn{3}{|c|}{ Predicted } \\
\hline & & \multicolumn{2}{|c|}{ Group } & \multirow{2}{*}{$\begin{array}{l}\text { Percentage } \\
\text { Correct }\end{array}$} \\
\hline \multirow{3}{*}{ Group } & & Ethanol & $\begin{array}{c}\text { Saline } \\
\text { Control }\end{array}$ & \\
\hline & Ethanol & 18 & 1 & 94.7 \\
\hline & Saline & 1 & 19 & 95 \\
\hline Overal & Percentage & & & 94.9 \\
\hline
\end{tabular}

\section{DISCUSSION}

We sought to understand whether binge intrauterine alcohol exposure would affect the rat diaphyseal and morphometric trabecular parameters using three-dimensional micro-focus X-ray computed tomography (3D- $\mu \mathrm{CT}$ ) at 3 weeks postpartum. Assessment of trabeculae volume, thickness, number and spacing in the proximal and distal epiphysis of the humerus showed altered trabecular parameters in the alcohol-exposed group. 
Table IV. Osteometricand distal epiphysis trabecular morphometric parameters in the logistic regression equation. BV/TV, bone volume to total volume; TbTh trabecular thickness; TbN, Trabecular number; TbSp, Trabecular spacing.

\begin{tabular}{|c|c|c|c|c|c|c|}
\hline \multicolumn{7}{|c|}{ Variables in the logistic regression equation } \\
\hline & $\mathrm{B}$ & S.E. & Wald & $\mathrm{df}$ & Sig. & $\operatorname{Exp}(B)$ \\
\hline \multicolumn{7}{|c|}{ Osteometric parameters } \\
\hline Length & -0.383 & 1.239 & 0.096 & 1 & 0.757 & 0.682 \\
\hline Epiphyseal volume & 0.353 & 0.753 & 0.219 & 1 & 0.640 & 1.423 \\
\hline \multicolumn{7}{|c|}{ Distal epiphysis trabecular morphometric parameters } \\
\hline $\mathrm{BV} / \mathrm{TV}$ & 87.847 & 39.006 & 5.072 & 1 & 0.024 & 1.418 \\
\hline TbTh & -24.851 & 33.818 & 0.540 & 1 & 0.462 & 0.001 \\
\hline $\mathrm{TbN}$ & 3.917 & 1.739 & 5.072 & 1 & 0.024 & 50.23 \\
\hline $\mathrm{TbSp}$ & 363.523 & 223.000 & 2.657 & 1 & 0.103 & 7.517 \\
\hline Constant & -97.313 & 44.921 & 4.693 & 1 & 0.030 & 0.000 \\
\hline
\end{tabular}

Table V. Group membership classification from humerus osteometricand distal epiphysis trabecular morphometric parameters.

\begin{tabular}{|c|c|c|c|c|}
\hline \multicolumn{5}{|c|}{ Classification table } \\
\hline \multirow{2}{*}{\multicolumn{2}{|c|}{ Observed }} & \multicolumn{3}{|c|}{ Predicted } \\
\hline & & \multicolumn{2}{|c|}{ Group } & Percentage Correct \\
\hline \multirow{3}{*}{ Group } & & Ethanol & Saline Control & \\
\hline & Ethanol & 17 & 2 & 89.5 \\
\hline & Saline Control & 4 & 15 & 78.9 \\
\hline \multicolumn{2}{|c|}{$\begin{array}{l}\text { Saline Control } \\
\text { Overall Percentage }\end{array}$} & & & 84.2 \\
\hline
\end{tabular}

In the present study, there were no significant differences in bone length among the three groups. Other studies (Nwaogu, 2002; Simpson et al.; Snow \& Keiver) found the length to be reduced in the ethanol group. The difference in the findings could be related to the dosage of ethanol administered to the dams. In the present study, we used $25.2 \%$ ethanol whereas other studies used a higher ethanol concentration of 30 and $36 \%$ in their studies (Nwaogu; Simpson et al.). The effects of prenatal ethanol exposure on bone are dose-dependent as Snow \& Keiver and Simpson et al. showed that $36 \%$ ethanol causes more adverse effects than $15 \%$ and $25 \%$ ethanol administered in gestation. A possibility exists that we could have found a shorter length in the ethanol group had we used a higher concentration such as $36 \%$.

Since length is a linear measurement in a single dimension, size information from other aspects in three-dimensional space tends to be excluded. The present study addressed this problem by incorporating volume estimates. The ethanol group had a lower epiphysis volume in both limbs compared to the controls. We could not find comparable studies that investigated this parameter. Also, the bone volume to total volume (BV/TV) was lower in the ethanol group in both limbs compared to the controls, only in the proximal epiphysis leaving the distal end unaffected. This could be attributed to the higher bone activity in the proximal than the distal end (Payton, 1933). We could not find BV/ TV literature that investigated gestational alcohol exposure prior to the current study. However, literature exists about postnatal alcohol consumption in animals showing alteration of BV/TV (Maddalozzo et al., 2009). Our study indicates that gestational alcohol effects may persist up to 3-weeks postnatally. Therefore, alcohol affects BV/TV despite stoppage after birth, with similar effects on BV/TV when alcohol is taken in postnatal life. Thinnest and fewer trabeculae with larger spacings were observed in the ethanol group in both limbs. Since trabeculae are a proxy for collagen deposition, thinner and fewer trabeculae in the present study suggest that fewer collagen fibres may have been deposited in the ethanol group. Postnatal alcohol use is known to impair osteoblast function (Martin \& Correa, 2010) and has a negative effect on trabecular number (Mikosch, 2014). Thinner trabeculae suggest that osteoblasts which produce collagen may have been adversely affected by alcohol. A possibility exists that intrauterine alcohol exposure may increase osteoclast activity, resorbing collagen fibres while also decreasing osteoblast activity to impede collagen synthesis. This phenomenon occurred in our study although the alcohol was only administered during gestation. 
The thinner and fewer trabeculae, with larger spaces in the ethanol group in both limbs, may be linked to bone weakness. Studies of postnatal alcohol intake report increased trabecular spacing (Maurel et al., 2012; Mikosch). This is thought to be due to an osteoclastic phase of bone loss contributing to ethanol-mediated osteoporosis. Children exposed to gestational alcohol during pregnancy, particularly those with FAS are at risk of osteoporosis and have a high bone fracture rate.

\section{CONCLUSIONS}

Our findings of thinner and fewer trabeculae with larger spacings in the ethanol group support the phenomenon of weak bones prone to osteoporosis and fracture. While no bone length differences occurred, the epiphyseal volume was affected by gestation ethanol. Logistic regression revealed that BV/TV and trabecular number were the most adversely affected parameters, which is a possible explanation of how gestational alcohol results in weaker bones during postnatal life.

PILLAY, D. \& NDOU, R. La exposición al alcohol intrauterino altera la morfología trabecular en la epífisis del húmero de la rata Sprague Dawley hasta 3 semanas después del nacimiento. Int. J. Morphol., 39(5):1436$1442,2021$.

RESUMEN: La exposición al alcohol durante la gestación inhibe el crecimiento y desarrollo neurológico y óseo tanto en la vida fetal como posnatal. Algunos de los efectos adversos incluyen la estatura atrofiada, osteoporosis y fracturas en la vida adulta. Si bien se ha estudiado el impacto del alcohol intrauterino en el cerebro, los estudios sobre los efectos en los huesos son escasos. Por lo tanto, nuestro estudio tuvo como objetivo examinar el impacto de la exposición prenatal al alcohol en la microarquitectura ósea en ratas de 3 semanas de edad utilizando Tomografía Computarizada de Rayos X Micro-focus (Micro CT). Las hembras de Sprague Dawley preñadas con apareamiento temporal (13) se colocaron aleatoriamente en 3 grupos: etanol $(n=5)$, control de solución salina $(\mathrm{n}=5)$ y control $\sin \operatorname{tratar}(\mathrm{n}=3)$. Los primeros 2 grupos recibieron tratamiento con $0,015 \mathrm{ml} / \mathrm{g}$ de etanol al $25,2 \%$ y solución salina al $0,9 \%$, respectivamente, durante los primeros 19 días de gestación. El grupo no tratado no recibió tratamiento. Las crías permanecieron con sus madres hasta la terminación a los 21 días de edad. De cada madre, se recolectaron 2 crías que dieron como resultado: etanol $(n=10)$, controles salinos $(n=$ 10) y controles no tratados $(n=6)$. Se diseccionaron y escanearon los húmero de las crías usando un escáner 3D- $\mu$ CT (Nikon XTH 225L) a una resolución de $15 \mu \mathrm{m}$. Los parámetros trabeculares y corticales se analizaron utilizando el software Volume Graphics Studio® después de la reconstrucción. Los resultados mostraron una disminución en el tamaño trabecular, los espacios, el grosor y el volumen. Hubo una disminución en el área del hueso cortical en el grupo de etanol en comparación con los controles. Estos hallazgos pueden sugerir que la osteoporosis y las fracturas por causa de los efectos del alcohol gestacional se pueden deber a una estructura trabecular comprometida.

PALABRA CLAVE: Microarquitectura; Trabéculas; Húmero; Osteoporosis; Alcohol prenatal.

\section{REFERENCES}

Bouxsein, M. L.; Boyd, S. K.; Christiansen, B. A.; Guldberg, R. E.; Jepsen, K. J. \& Müller, R. Guidelines for assessment of bone microstructure in rodents using micro-computed tomography. J. Bone Miner. Res., 25(7):1468-86, 2010.

Chaudhuri, J. D. Alcohol and the developing fetus--a review. Med. Sci. Monit., 6(5):1031-41, 2000.

Chen, G.; Deng, C. \& Li, Y. P. TGF-b and BMP signaling in osteoblast differentiation and bone formation. Int. J. Biol. Sci., 8(2):272-88, 2012.

Maddalozzo, G. F.; Turner, R. T.; Edwards, C. H.; Howe, K. S.; Widrick, J. J.; Rosen, C. J. \& Iwaniec, U. T. Alcohol alters whole body composition, inhibits bone formation, and increases bone marrow adiposity in rats. Osteoporos. Int., 20(9):1529-38, 2009.

Martin, R. M. \& Correa, P. H. S. Bone quality and osteoporosis therapy. Arq. Bras. Endocrinol. Metabol., 54(2):186-99, 2010.

Maurel, D. B.; Boisseau, N.; Benhamou, C. L. \& Jaffre, C. Alcohol and bone: review of dose effects and mechanisms. Osteoporos. Int., 23(1):116, 2012.

Mikosch, P. Alcohol and bone. Wien. Med. Wochenschr., 164(1-2):15-24, 2014.

Miralles-Flores, C. \& Delgado-Baeza, E. Histomorphometric analysis of the epiphyseal growth plate in rats after prenatal alcohol exposure. $J$. Orthop. Res., 10(3):325-36, 1992.

Nwaogu, I. C. Foetal alcohol syndrome: growth rate of bones in rats. $J$. Appl. Anim. Res., 22(2):249-53, 2002.

Payton, C. G. The growth of the epiphyses of the long bones in the madderfed pig. J. Anat., 67(Pt. 3):371-81, 1933.

Popova, S.; Lange, S.; Probst, C.; Parunashvili, N. \& Rehm, J. Prevalence of alcohol consumption during pregnancy and Fetal Alcohol Spectrum Disorders among the general and Aboriginal populations in Canada and the United States. Eur. J. Med. Genet., 60(1):32-48, 2017.

Simpson, M. E.; Duggal, S. \& Keiver, K. Prenatal ethanol exposure has differential effects on fetal growth and skeletal ossification. Bone, 36(3):521-32, 2005

Snow, M. E. \& Keiver, K. Prenatal ethanol exposure disrupts the histological stages of fetal bone development. Bone, 41(2):181-7, 2007.

Tomlinson, M.; O'Connor, M. J.; le Roux, I. M.; Stewart, J.; Mbewu, N.; Harwood, J. \& Rotheram-Borus, M. J. Multiple risk factors during pregnancy in South Africa: the need for a horizontal approach to perinatal care. Prev. Sci., 15(3):277-82, 2014.

Corresponding author:

Dr Diana Pillay

School of Anatomical Sciences

Faculty of Health Sciences

University of Witwatersrand

7 York Road

Parktown

Johannesburg 2193

SOUTH AFRICA

E-mail: diana.pillay@wits.ac.za

Received: 02-06-2021

Accepted: 07-07-2021 